\title{
Compositional effect on TCP phase formation in Ru-containing Ni-based single crystal superalloys
}

\author{
Qianying $\mathrm{Shi}^{1}$, Jiajie $\mathrm{Huo}^{2}$, Lamei $\mathrm{Cao}^{3}, \mathrm{Jie} \mathrm{Li}^{2,4}$, Xianfei Ding ${ }^{2}$, Yunrong Zheng ${ }^{2}$, and Qiang Feng ${ }^{1,2, a}$ \\ ${ }^{1}$ State Key Laboratory for Advanced Metals and Materials, University of Science and Technology Beijing, Beijing \\ 100083, China \\ ${ }^{2}$ National Center for Materials Service Safety, University of Science and Technology Beijing, Beijing 100083, China \\ ${ }^{3}$ Science and Technology on Advanced High Temperature Structural Materials Laboratory, Beijing Institute of \\ Aeronautical Materials, Beijing 100095, China \\ ${ }^{4}$ China Iron and Steel Research Institute Group, Beijing 100081, China
}

\begin{abstract}
Microstructural instability involving the formation of topologically close-packed (TCP) phases is restricted during the alloy development of Ni-based single crystal superalloys. In this study, the effects of alloying elements including $\mathrm{Co}, \mathrm{Cr}$, Mo and $\mathrm{Ru}$ on the formation of different TCP phases were investigated in a series of single crystal superalloys. Experimental results showed that more additions of $\mathrm{Cr}$ and Mo promoted the TCP phase formation, while $\mathrm{Co}$ and $\mathrm{Ru}$ played a positive role in improving microstructural stability. It is indicated that $\sigma, \mathrm{P}$ and $\mathrm{R}$ phases existed with various morphology and compositions in different experimental alloys during thermal exposure at $1100{ }^{\circ} \mathrm{C}$. The content of $\mathrm{Co}, \mathrm{Cr}$ and Mo in those alloys affected the types of TCP phases significantly, while Ru additions showed a negligible effect. $\mathrm{R}$ phase was prone to form in alloys containing high level of Co addition. Meanwhile, the ratio of $\mathrm{Cr}$ and Mo content had strong influence on the formation of $\sigma$ and $\mathrm{P}$ phases in alloys containing low level of Co addition. The effects of alloying additions on the elemental partitioning ratios between $\gamma$ and $\gamma^{\prime}$ phases contributed to their corresponding influence on TCP phase formation.
\end{abstract}

\section{Introduction}

Ni-based single crystal superalloys with superior mechanical properties at high temperature are widely used for turbine blades in aircraft engines. Micro-structural instability, especially the precipitation of topologically close packed (TCP) phases, should be avoided during alloy development [1]. Many studies indicate that TCP phases, such as $\sigma, \mu, \mathrm{P}$ and $\mathrm{R}$ phases, are detrimental to mechanical properties, since their hard and brittle nature causes damage accumulation or cracking and their formation depletes the strengthening elements of the $\gamma$ matrix $[2,3]$.

The precipitation behavior (morphology, composition and kinetics) of different types of TCP phases is influenced by different alloying additions in commercial Ni-based superalloys, which usually contain a combination of five to ten other elements up to $40 \mathrm{wt}$.\% besides $\mathrm{Ni}$ [4]. Refractory alloying elements with large differences in electronic structure and atomic radii compared to $\mathrm{Ni}$, such as $\mathrm{Mo}, \mathrm{W}$ and especially $\mathrm{Re}$, are added for significant solid solution strengthening of the $\gamma$ matrix in superalloys [4]. Moreover, as one of indispensable alloying elements, $\mathrm{Cr}$ is beneficial to hot corrosion and oxidation resistance and also an effective solid solution strengthening element [5]. However, the excessive additions of above mentioned elements were reported to promote the TCP phase formation in $\mathrm{Ni}$ -

\footnotetext{
${ }^{a}$ Corresponding author: qfeng@skl.ustb.edu.cn
}

based superalloys [4-6]. As an effective suppressor of TCP phases, $\mathrm{Ru}$ was added into the fourth generation single crystal superalloys to improve the microstructural stability and creep properties [7-9]. However, the mechanism is not quite clear yet, and more $\mathrm{Ru}$ additions increase the cost of new generation single crystal superalloys. Furthermore, Co additions were found to prevent the formation of TCP phases in some superalloys [8,10-12], although there has been still controversy associated with the effect of Co additions on microstructural stability $[13,14]$.

Alloying effects on microstructural stability, creep capability, environmental resistance and economic cost should be balanced for further alloy development. Although the excessive additons of $\mathrm{Cr}$ and Mo could induce a negative effect on microstructural stability, their additions benefit the improvement of creep properties $[15,16]$. Therefore, it is worthy to evaluate the effects of $\mathrm{Cr}$ and Mo additions and maximize their capacity to increase the creep resistance. This will provide the possibility to decrease the level of $\mathrm{Re}$ additions, which increases the density and cost of advanced single crystal superalloys and limits their practical application. Since Co was considered to be a potential microstructural stabilizer in previous studies $[8,17,18]$, the role of Co additions in advanced single crystal superalloys should be assessed to investigate whether it is applicable to add more Co as a substitute for a part of expensive Ru to achieve acceptable alloy stability.

This is an Open Access article distributed under the terms of the Creative Commons Attribution License 4.0, which permits unrestricted use, distribution, and reproduction in any medium, provided the original work is properly cited. 
Table 1. Measured chemical compositions (wt.\%/at.\%) and $\overline{N_{v}}$ values of experimental single crystal superalloys.

\begin{tabular}{|l|l|l|l|l|l|l|l|l|l|l|l|}
\hline Alloy & Ni & Al & Co & Cr & Mo & Re & Ru & Ta & W & Hf & $\overline{N_{v}}$ \\
\hline SC1111 & Bal. & $6.0 / 14.0$ & $\mathbf{7 . 1 / 7 . 6}$ & $\mathbf{3 . 6 / 4 . 4}$ & $\mathbf{1 . 0} / \mathbf{0 . 7}$ & $4.4 / 1.5$ & $\mathbf{2 . 6 / 1 . 6}$ & $7.9 / 2.7$ & $5.4 / 1.9$ & $0.1 / 0.04$ & 1.95 \\
\hline SC2111 & Bal. & $6.1 / 14.1$ & $\mathbf{1 5 . 0 / 1 5 . 9}$ & $\mathbf{3 . 5 / 4 . 2}$ & $\mathbf{1 . 0} / \mathbf{0 . 7}$ & $4.2 / 1.4$ & $\mathbf{2 . 7 / 1 . 7}$ & $8.1 / 2.8$ & $5.5 / 1.9$ & $0.1 / 0.04$ & 2.28 \\
\hline SC1211 & Bal. & $6.0 / 13.7$ & $\mathbf{6 . 9 / 7 . 2}$ & $\mathbf{6 . 5 / 7 . 7}$ & $\mathbf{1 . 0} / \mathbf{0 . 6}$ & $4.0 / 1.3$ & $\mathbf{2 . 6 / 1 . 6}$ & $7.9 / 2.7$ & $5.4 / 1.8$ & $0.1 / 0.03$ & 2.30 \\
\hline SC1121 & Bal. & $6.0 / 13.9$ & $\mathbf{6 . 9} / 7.4$ & $\mathbf{3 . 5} / \mathbf{4 . 2}$ & $\mathbf{2 . 4 / 1 . 6}$ & $4.1 / 1.4$ & $\mathbf{2 . 7 / 1 . 7}$ & $8.0 / 2.8$ & $5.5 / 1.9$ & $0.1 / 0.04$ & 2.03 \\
\hline SC1112 & Bal. & $6.0 / 14.1$ & $\mathbf{6 . 9 / 7 . 4}$ & $\mathbf{3 . 5 / 4 . 3}$ & $\mathbf{1 . 0} / \mathbf{0 . 7}$ & $4.0 / 1.4$ & $\mathbf{4 . 0 / 2 . 5}$ & $8.0 / 2.8$ & $5.4 / 1.9$ & $0.1 / 0.04$ & 1.98 \\
\hline SC2221 & Bal. & $6.0 / 13.8$ & $\mathbf{1 4 . 4 / 1 5 . 3}$ & $\mathbf{6 . 2 / 7 . 4}$ & $\mathbf{2 . 2 / 1 . 4}$ & $4.0 / 1.3$ & $\mathbf{2 . 6 / 1 . 6}$ & $8.0 / 2.7$ & $5.3 / 1.8$ & $0.1 / 0.03$ & 2.66 \\
\hline SC2212 & Bal. & $6.0 / 13.9$ & $\mathbf{1 4 . 4 / 1 5 . 2}$ & $\mathbf{6 . 1 / 7 . 3}$ & $\mathbf{1 . 0 / 0 . 6}$ & $3.9 / 1.3$ & $\mathbf{3 . 7 / 2 . 3}$ & $7.9 / 2.7$ & $5.3 / 1.8$ & $0.1 / 0.03$ & 2.60 \\
\hline SC2122 & Bal. & $6.1 / 14.2$ & $\mathbf{1 4 . 5 / 1 5 . 5}$ & $\mathbf{3 . 5 / 4 . 2}$ & $\mathbf{2 . 4 / 1 . 5}$ & $4.0 / 1.3$ & $\mathbf{3 . 9} / \mathbf{2 . 4}$ & $8.0 / 2.8$ & $5.4 / 1.9$ & $0.1 / 0.04$ & 2.44 \\
\hline SC1222 & Bal. & $6.0 / 13.7$ & $\mathbf{6 . 7 / 7 . 1}$ & $\mathbf{5 . 7 / 7 . 0}$ & $\mathbf{2 . 1 / 1 . 4}$ & $3.9 / 1.3$ & $\mathbf{3 . 6 / 2 . 2}$ & $7.8 / 2.7$ & $5.3 / 1.8$ & $0.1 / 0.04$ & 2.32 \\
\hline
\end{tabular}

Consequently, on the basis of balancing the individual elemental effects, a series of single crystal superalloys containing different levels of $\mathrm{Co}, \mathrm{Cr}$, Mo and $\mathrm{Ru}$ additions were designed in this study. An understanding of the individual and synergetic effects of four alloying elements on the formation of TCP phases was acquired through the current work. The information about TCP phase formation in Ru-containing superalloys is helpful to design alloys with better microstructural stability and complement the thermodynamic modelling database.

\section{Experimental}

The measured chemical compositions of experimental alloys are listed in Table 1. Four elements ( $\mathrm{Co}, \mathrm{Cr}$, Mo and $\mathrm{Ru}$ ) were assigned in two levels of contents: low and high (Co: 7.0 wt.\% and 15.0 wt.\%; Cr: 3.5 wt.\% and 6.0 wt.\%; Mo: 1.0 wt.\% and 2.5 wt. \%; Ru: 2.5 wt.\% and 4.0 wt.\%). These alloys were named as SC plus four numbers, which in turn represented the level of $\mathrm{Co}, \mathrm{Cr}$, Mo and $\mathrm{Ru}$ additions (" 1 " and " 2 " denoting the low and high level of individual elements, respectively). It should be noted that the compositional feature of eight alloys SC2111 SC1222 is in accordance with the factorial design and then it is applicable to employ associated analysis methods.

These experimental alloys were directionally solidified as single crystal bars with the growth orientation $\langle 001\rangle$ (15 $\mathrm{mm}$ in diameter and $150 \mathrm{~mm}$ in length) at the Beijing Institute of Aeronautical Materials. The cast experimental alloys were solution heat treated at high temperature in the range of $1300{ }^{\circ} \mathrm{C} \sim 1335^{\circ} \mathrm{C}$ for $8 \sim 16 \mathrm{~h}$, and then aged at $1150{ }^{\circ} \mathrm{C}$ for $4 \mathrm{~h}$ and at $870^{\circ} \mathrm{C}$ for $24 \mathrm{~h}$. Following such standard heat treatments, thermal exposure at $1100{ }^{\circ} \mathrm{C}$ for different times was performed in order to investigate the alloying effect on the TCP phase formation in these Rucontaining Ni-based single crystal superalloys.

The cross-sectional microstructures perpendicular to the growth orientation of single crystal bars were prepared by the standard metallographic procedure. The TCP precipitates in alloys exposed at $1100^{\circ} \mathrm{C}$ for $500 \mathrm{~h}$ were separated through the electrolytic phase extraction method in a solution of 9:1 Methanol: $\mathrm{HCl}+1 \mathrm{wt} . \%$ tartaric acid with a current density of $0.04 \mathrm{~A} / \mathrm{cm}^{2}$, using a stainless steel sheet as a cathode. Microstructural examination was performed using a ZEISS SUPRA 55 field-emission scanning electron microscope (FE-SEM) with an equipped energy-dispersive spectroscope (EDS). Five images taken in the SEM-BSE mode were used for determining the
Table 2. Volume fraction of TCP precipitates in dendrite cores of experimental alloys after thermal exposure at $1100^{\circ} \mathrm{C}$ for different times $(\%)$.

\begin{tabular}{|l|l|l|l|l|}
\hline Alloy & $\mathbf{1 0 h}$ & $\mathbf{5 0 h}$ & $\mathbf{2 0 0 h}$ & $\mathbf{5 0 0 h}$ \\
\hline SC1111 & - & - & $*$ & $*$ \\
\hline SC2111 & - & - & $*$ & $*$ \\
\hline SC1211 & $6.12 \pm 0.42$ & $10.86 \pm 0.32$ & $11.23 \pm 1.06$ & $11.87 \pm 1.014$ \\
\hline SC1121 & $1.20 \pm 0.25$ & $5.29 \pm 0.66$ & $5.26 \pm 0.22$ & $5.65 \pm 1.094$ \\
\hline SC1112 & - & - & - & $*$ \\
\hline SC2221 & $0.65 \pm 0.31$ & $4.23 \pm 1.51$ & $5.39 \pm 0.54$ & $5.78 \pm 0.75$ \\
\hline SC2212 & $*$ & $*$ & $0.44 \pm 0.06$ & $1.19 \pm 0.38$ \\
\hline SC2122 & $*$ & $*$ & $0.54 \pm 0.16$ & $1.26 \pm 0.47$ \\
\hline SC1222 & $8.84 \pm 0.87$ & $8.68 \pm 0.41$ & $11.53 \pm 0.54$ & $10.17 \pm 0.79$ \\
\hline
\end{tabular}

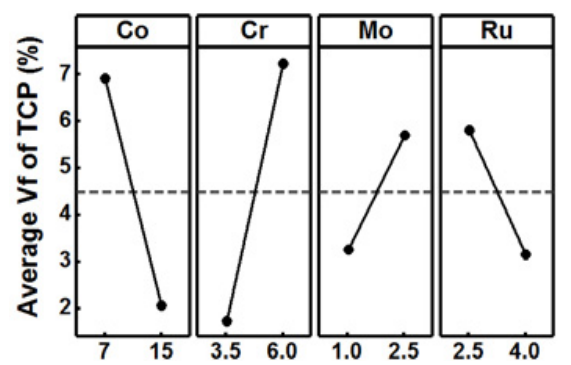

Figure 1. Main effect plots generated by using the volume fractions of TCP precipitates in dendrite cores of alloys SC2111 SC1222 after thermal exposure at $1100^{\circ} \mathrm{C}$ for $500 \mathrm{~h}$.

volume fraction of TCP precipitates in each sample through counting the area ratio of TCP phases by using ImagePro Plus software. In order to identify TCP phases, $\mathrm{X}$-ray diffraction (XRD) patterns were obtained from the electrolytic phase extracted residues by Rigaku D/max$\mathrm{RB} 12$ diffractometer with $\mathrm{Cu} \mathrm{K} \alpha$ radiation. TEM analyses of the TCP extraction were also carried out to confirm the type of TCP phases in each alloy through selected area electron diffraction patterns using a Tecnai F30 transmission electron microscope.

Electrolytic phase extraction procedure was employed on the alloys after the standard heat treatments to separate the $\gamma^{\prime}$ phase. The compositions of $\gamma$ and $\gamma^{\prime}$ phases were obtained through chemical analyses on the residual liquor and residue, respectively. The partitioning ratios of alloying elements between $\gamma$ and $\gamma^{\prime}$ phase, $k_{i}$, were calculated through the equation $k_{i}=c_{\gamma}^{i} / c_{\gamma^{\prime}}^{i}, k_{i}$ greater or less than unity means that the element $i$ partitions to $\gamma$ or $\gamma^{\prime}$ phase. 


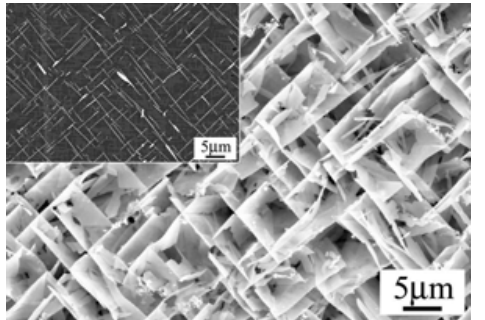

(a)

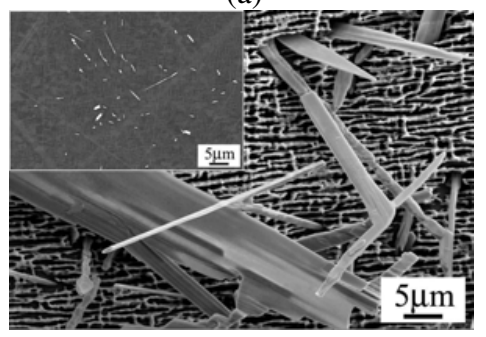

(d)

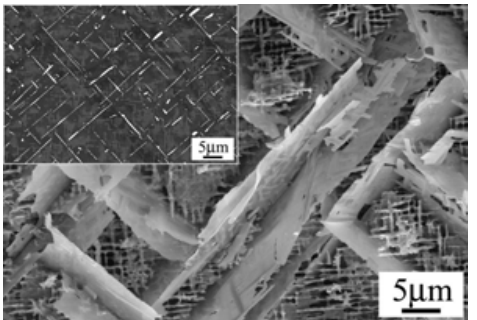

(b)

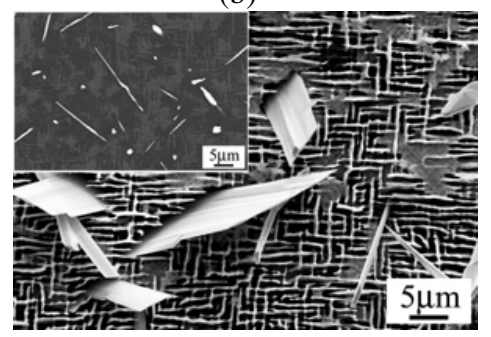

(e)

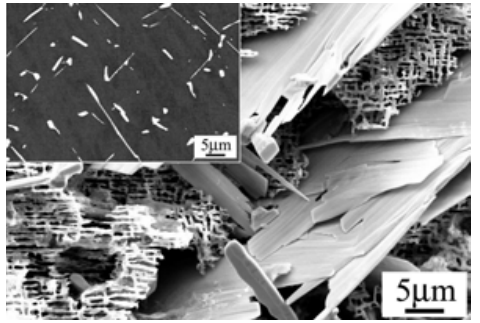

(c)

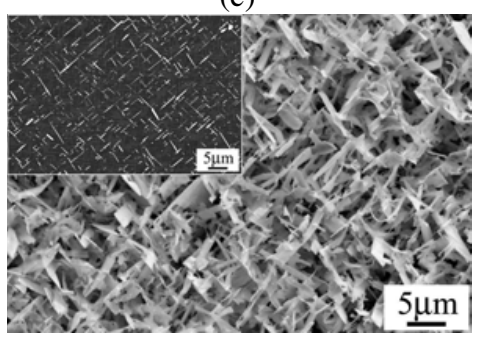

(f)

Figure 2. Two-dimensional and three-dimensional morphology of TCP precipitates in experimental alloys after thermal exposure at $1100^{\circ} \mathrm{C}$ for 500 h. (a) Alloy SC1211; (b) Alloy SC1121; (c) Alloy SC2221; (d) Alloy SC2212; (e) Alloy SC2122; (f) Alloy SC1222.

\section{Results}

\subsection{The formation of TCP phases}

Table 2 shows the volume fraction of TCP precipitates in dendrite cores of experimental alloys after thermal exposure at $1100{ }^{\circ} \mathrm{C}$ for time in the range of $10 \mathrm{~h}$ to $500 \mathrm{~h}$. It is indicated that these experimental alloys have different tendencies to form TCP phases due to different levels of $\mathrm{Co}, \mathrm{Cr}$, Mo and $\mathrm{Ru}$ additions. Compared with alloy SC1111, the fact regarding the volume fractions of TCP precipitates in alloys SC1211 and SC1121 indicates that high $\mathrm{Cr}$ and Mo contents strongly promoted the TCP phase formation. The further statistical analyses were carried out by using MINITAB software, which generated the plots of main effects to assess the influence of individual elements within alloys SC2111 SC1222. Figure 1 demonstrates the main effects of four elements generated by using the volume fractions of TCP precipitates in dendrite cores of these eight alloys after thermal exposure at $1100^{\circ} \mathrm{C}$ for $500 \mathrm{~h}$. The negative effect of $\mathrm{Cr}$ and Mo additions on microstructural stability was again confirmed. In addition, it is indicated that high level of $\mathrm{Co}$ and $\mathrm{Ru}$ additions decreased the formation of TCP precipitates.

The two-dimensional and three-dimensional morphologies of TCP precipitates in six experimental alloys after thermal exposure at $1100{ }^{\circ} \mathrm{C}$ for $500 \mathrm{~h}$ are shown in Fig. 2. For alloys SC1211, SC1121 and SC1222, most of TCP precipitates exhibited a needle-like shape in twodimension, as exhibited in those inserted images at the upper left of Figs. 2a, 2b and 2f. Furthermore, TCP precipitates in alloys SC1211 and SC1222 (Figs. 2a and 2f) appeared to be smooth sheets in three-dimension, which were taken from the phase extracted residues in the matrix. But TCP precipitates in alloy SC1121 showed the sheet morphology with the basket weave in threedimension (Fig. 2b). As shown in Figs. 2c, 2d and 2e, TCP precipitates in three alloys SC2221, SC2212 and SC2122 primarily appeared to be broadsword-like, and some of them were shown to be short rod-like and needlelike. XRD analyses of the extracted residues in alloys after thermal exposure at $1100^{\circ} \mathrm{C}$ for $500 \mathrm{~h}$ identified TCP precipitates with different morphologies as different types of TCP phases. Strong peaks of the matrix were observed in all spectra of Figs. 3a-c, suggesting that the extracted TCP precipitates were contaminated by a varying amount of the matrix during the electrolytic phase extraction procedure. A number of peak locations of $\sigma$ phase (Fig. 3a) showed the considerable correspondence with the TCP precipitates in alloys SC1211 and SC1222. P phase was found to be the best-fitting TCP phase in alloy SC1121 (Fig. 3b), while R phase matched to the majority of diffraction peak locations obtained from the samples of alloys SC2221, SC2212 and SC2122 (Fig. 3c). Figure 4 shows the selected area electron diffraction patterns of $\sigma$, $\mathrm{P}$ and $\mathrm{R}$ phases obtained on the extracted phase residues of alloys SC1211, SC1121 and SC2212. These TEM analyses confirmed the different TCP phases existing in these experimental alloys.

Figure 5 presents the compositional features of different TCP phases, which were obtained through SEMEDS analyses on the extracted residues of TCP phases in these experimental alloys after thermal exposure at $1100{ }^{\circ} \mathrm{C}$ for $500 \mathrm{~h}$. Figures $5 \mathrm{a}$ and $5 \mathrm{~b}$ show that TCP precipitates (mainly $\sigma$ phase) in alloys SC1211 and SC1222 as well as TCP precipitates (mainly $\mathrm{P}$ phase) in alloy SC1121 contained lower Co concentration, while the Co content of the TCP precipitates (mainly R phase) in alloys SC2221, SC2212 and SC2122 was higher (Fig. 5c). The contents of $\mathrm{Cr}$ and $\mathrm{Mo}$ were approximate in $\mathrm{P}$ phase (Fig. 5b), but the ratio of $\mathrm{Cr}$ and Mo concentrations was relatively higher in $\sigma$ phase (Fig. 5a). The slight difference in the Ru content of TCP phases in six experimental alloys was observed in Figs. 5a-c. In addition, Re concentration of $\sigma$ phase in alloys SC1211 and SC1222 (Fig. 5a) was observed to be higher than in other TCP phases (Figs. 5b and 5c). In fact, the overall compositions of 


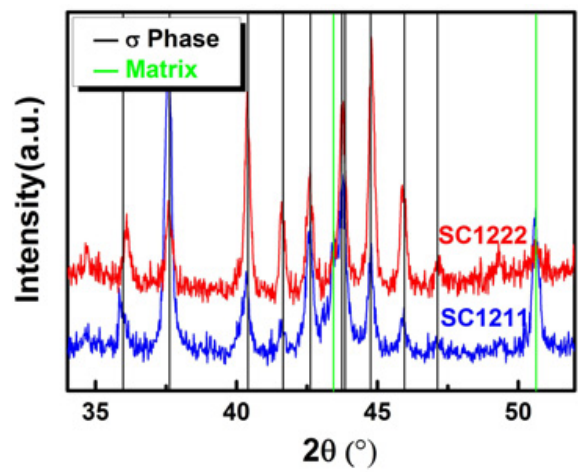

(a)

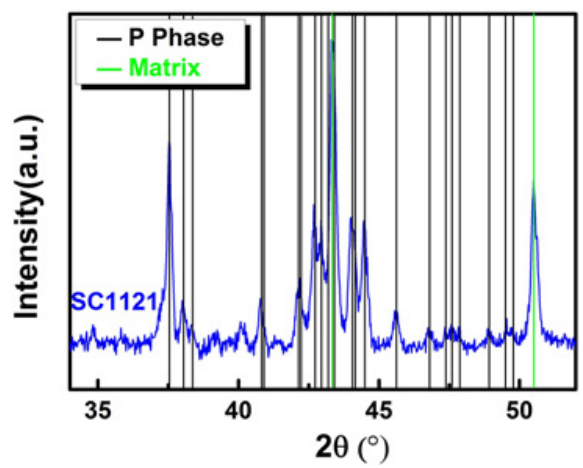

(b)

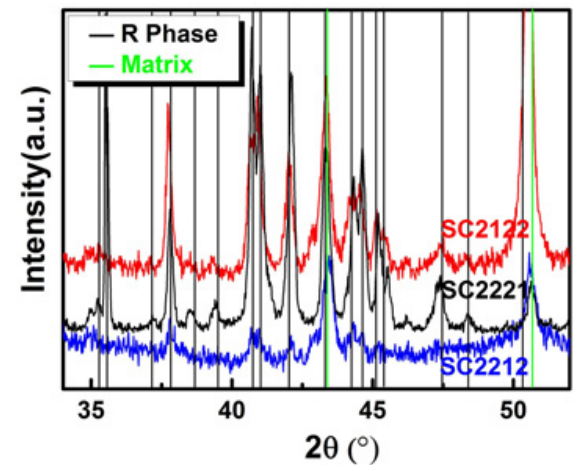

(c)

Figure 3. X-ray diffraction patterns of the extracted TCP phases in experimental alloys after thermal exposure at $1100^{\circ} \mathrm{C}$ for 500 h. (a) Alloys SC1211 and SC1222; (b) Alloy SC1121; (c) Alloys SC2221, SC2212 and SC2122.

experimental alloys with different levels of $\mathrm{Co}, \mathrm{Cr}$, Mo and $\mathrm{Ru}$ additions influenced the compositional features of those TCP phases in each alloy. Therefore, it is suggested that the content of $\mathrm{Co}, \mathrm{Cr}$ and Mo affected the types of TCP phases significantly, while Ru addition showed a negligible effect. $\mathrm{R}$ phase was prone to form in alloys containing high level of $\mathrm{Co}$ addition (Co concentration in alloys SC2221, SC2212 and SC2122 was at the high level, $\sim 15.0$ wt.\%). Meanwhile, the ratio of $\mathrm{Cr}$ and Mo contents $(\mathrm{Cr} / \mathrm{Mo})$ had strong influence on the formation of $\sigma$ and $\mathrm{P}$ phases in alloys containing low level of Co addition (Co concentration in alloys SC1211, SC1222 and SC1121 was at the low level, $7.0 \mathrm{wt} . \%$ ). The $\mathrm{Cr} / \mathrm{Mo}$ ratios in atomic percent in alloys SC1211 and SC1222 with $\sigma$ phase

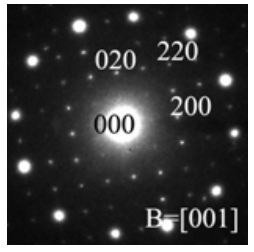

(a)

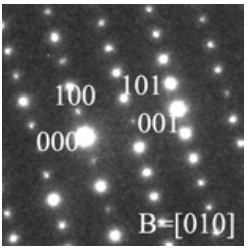

(b)

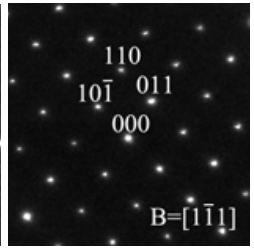

(c)
Figure 4. Selected area electronic diffraction patterns of the TCP extraction in the experimental alloys after thermal exposure at $1100{ }^{\circ} \mathrm{C}$ for $500 \mathrm{~h}$. (a) $\sigma$ phase in alloy $\mathrm{SC} 1211$; (b) P phase in alloy SC1121; (c) R phase in alloy SC2212.

formation were 12.23 and 4.93, higher than that in alloy SC1121 (2.68) with P phase formation.

\subsection{Elemental partitioning ratios between $\gamma$ and $\gamma^{\prime}$ phases}

Similar to the elemental partitioning behavior in the majority of Ni-based single crystal superalloys, chemical analyses of $\gamma$ and $\gamma^{\prime}$ phases showed that $\mathrm{Al}$ and Ta partitioned into the $\gamma^{\prime}$ phase, while $\mathrm{Cr}, \mathrm{Mo}, \mathrm{Re}$ and $\mathrm{Ru}$ enriched the $\gamma$ phase. Additionally, it should be mentioned that the partitioning ratio of $\mathrm{W}$ between $\gamma$ and $\gamma^{\prime}$ phases was slightly less than or near to unity in these experimental alloys, which could be attributed to the presence of $\mathrm{Re}$ and $\mathrm{Ru}$. Additions of $\mathrm{Co}, \mathrm{Cr}, \mathrm{Mo}$ and $\mathrm{Ru}$ influenced the partitioning behaviors of themselves and other alloying elements. Figure 6 exhibits the main effects of these four elements on the partitioning ratios of TCP-forming elements (Cr, Mo, Re and W). It is indicated that more Co and $\mathrm{Ru}$ additions decreased the partitioning ratios of $\mathrm{Cr}$, Mo, Re and $\mathrm{W}$ to different degrees, while increasing $\mathrm{Cr}$ and Mo contents induced the opposite effect.

\section{Discussion}

The average electron vacancy concentration $\left(\overline{N_{v}}\right)$ assigned by considering the electron vacancy number of each element is usually used to predict the formation of TCP phases, since TCP phases are considered as electron compounds $[19,20]$. Alloys are considered to be TCPprone if their $\overline{N_{v}}$ values are above an empirically determined value $\left(\overline{N_{\nu c}}\right)$, which varies much in different $\mathrm{Ni}$ based superalloy systems. $\overline{N_{v}}$ values of these investigated single crystal superalloys in this study were calculated according to the AS5491C standard [21] (as listed in Table 1). Experimental results (Tables 1 and 2) indicated that the alloys with the $\overline{N_{v}}$ value higher than 2.0 had stronger tendency to form TCP phases during the thermal exposure process. However, the volume fraction of TCP precipitates in alloy SC2111 with the $\overline{N_{v}}$ value 2.28 was nearly zero even after thermal exposure at $1100{ }^{\circ} \mathrm{C}$ for $500 \mathrm{~h}$. Based on the overall composition of alloy SC2111 and the contribution of individual alloying element to the $\overline{N_{v}}$ value, it is considered that high level of Co additions caused the relatively higher $\overline{N_{v}}$ value in alloy SC2111. In general, decreasing the level of Co additions in Ni-based superalloys should have a beneficial effect on microstructural stability, since the electron vacancy 


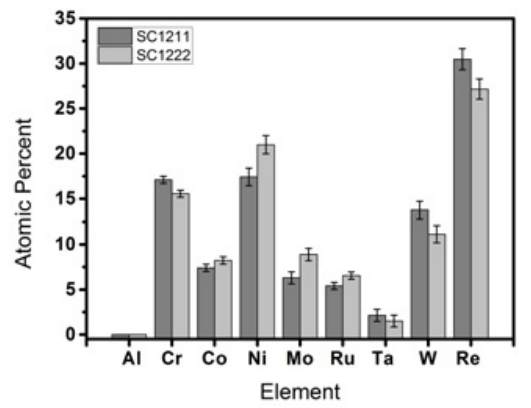

(a)

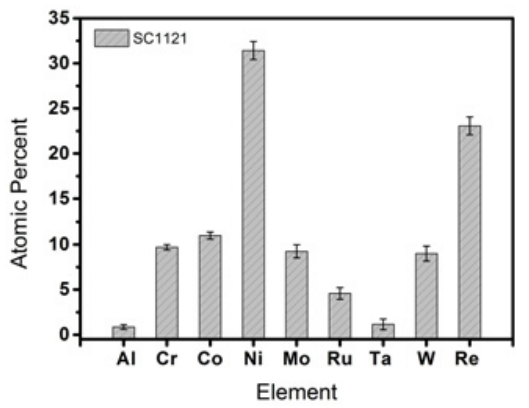

(b)

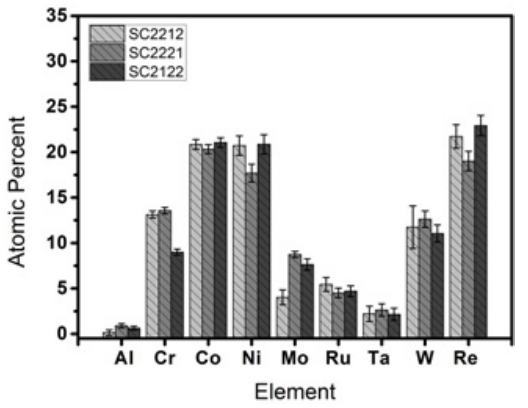

(c)

Figure 5. Compositions of TCP precipitates obtained through SEM-EDS analyses on the extracted residues in experimental alloys after thermal exposure at $1100^{\circ} \mathrm{C}$ for $500 \mathrm{~h}$. (a) Alloys SC1211 and SC1222; (b) Alloy SC1121; (c) Alloys SC SC2221, SC2212 and SC2122.

number of $\mathrm{Co}$ (1.61) is higher than that of $\mathrm{Ni}(0.66)$ [13]. Bürgel's study on directionally solidified superalloys showed that Co-free alloy had comparatively more stable microstructure with respect to TCP phase formation than the similar alloy containing 4 wt.\% Co [13]. Erickson claimed that lower Co concentrations in a third generation single crystal superalloy CMSX-10 led to the attainment of acceptable alloy stability [14]. However, Co additions were found to prevent the formation of $\sigma$ phase and $\mu$ phase in superalloy MAR-M421 [10] and single crystal superalloy MAR-M247 [11], respectively. Moreover, Walston et al. suggested that high levels of Co additions could induce the reverse partitioning of alloying elements and then improve the resistance to TCP phase formation in a fourth generation single crystal superalloy [8]. Rae's study suggested that Co suppressed the nucleation of the $\sigma$ phase by altering the $\gamma$ lattice parameter, which was attributed to the redistribution of elements between $\gamma$ and $\gamma^{\prime}$ phases [6]. Wang's work on a series of single crystal superalloys also demonstrated that TCP phase formation was suppressed by promoting the diffusion process due to more Co additions [12]. In the current study, higher Co addition was showed to be beneficial for the suppression of TCP phase formation, which was attributed to its influence on the elemental partitioning behavior of the TCP-forming elements such as Re, Cr, Mo and W (Fig. 6).

Since the thermodynamic driving force for TCP phases formation results from the solute supersaturation of $\gamma$ matrix, the elemental partitioning between $\gamma$ and $\gamma^{\prime}$ phases, especially refractory alloying elements such as $\mathrm{Re}$, Mo and $\mathrm{W}$ as well as $\mathrm{Cr}$, has strong influence on the formation of TCP phases. It was early reported that $\mathrm{Ru}$ additions induced the reverse partitioning behavior of alloying elements between the $\gamma$ and $\gamma^{\prime}$ phases and then suppressed the formation of TCP phases [7]. However, later studies provided contradictory results about the effect of $\mathrm{Ru}$ additions on the elemental partitioning behavior $[8,15,22,23]$. In the current study, increasing Ru addition from $\sim 2.5 \mathrm{wt} . \%$ to $\sim 4.0 \mathrm{wt} . \%$ decreased the partitioning ratio of those TCP-forming elements to different degrees (Fig. 6). And more Co additions play the similar role with $\mathrm{Ru}$. This contributed to their suppressive effect on the TCP phase formation. However, increasing $\mathrm{Cr}$ and Mo contents increased the partitioning ratios of the TCPforming elements (Fig. 6). In addition, $\mathrm{Cr}$ and Mo were considered as the TCP-forming elements. Accordingly, the

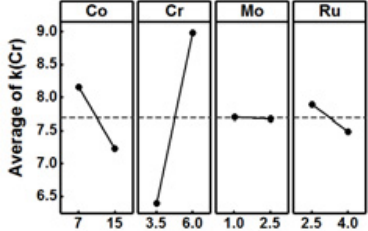

(a)

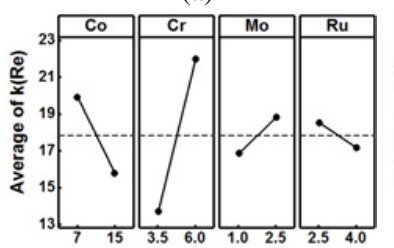

(c)

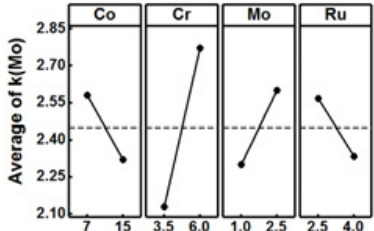

(b)

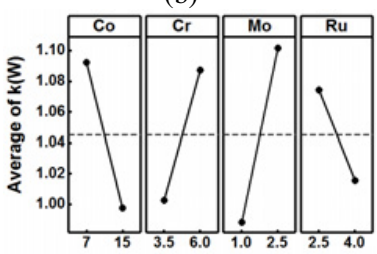

(d)
Figure 6. Main effect plots generated by using the elemental partitioning ratios between $\gamma$ and $\gamma^{\prime}$ phases of alloys SC2111 ${ }^{\sim} \mathrm{SC} 1222$ after the standard heat treatment. (a) $k_{C r}$; (b) $k_{M o}$; (c) $k_{R e} ;$ (d) $k_{W}$.

TCP phase formation was promoted by more $\mathrm{Cr}$ and $\mathrm{Mo}$ additions.

There are limited reports about the effect of alloying additions on the type of TCP phases. Hobb's work suggested that $\mathrm{Ru}$ additions affected the compositions of TCP and $\gamma$ phases as well as their lattice parameters, but no change was observed in the type of TCP phases and the crystallographic orientation relationships between TCP precipitates and matrix [24]. Rae's study reported that increasing the ratio between Mo and $\mathrm{W}$ contents stabilized $\mathrm{P}$ phase and increasing $\mathrm{Cr}$ and $\mathrm{Re}$ additions stabilized $\sigma$ phase [6]. Karunaratne et al claimed that $\mathrm{Cr} / \mathrm{Mo}$ ratio was a good way for distinguishing between various TCP phases, but the calculated values were not in complete agreement with their experimental results [25]. In the current study, the $\operatorname{Re}$ concentration in the $\sigma$ phase was higher than those of $\mathrm{P}$ and $\mathrm{R}$ phases, while $\mathrm{Ru}$ concentration was similar in three TCP phases (Fig. 5). The content of Co, $\mathrm{Cr}$ and $\mathrm{Mo}$ in experimental alloys affected the type of TCP phases significantly. $\mathrm{R}$ phase was prone to form in alloys containing high level of Co addition. $\sigma$ and $\mathrm{P}$ phases were found in alloys containing low level of Co addition. Meanwhile, the ratio of $\mathrm{Cr}$ and Mo contents had strong influence on the formation of $\sigma$ and $\mathrm{P}$ phases. The $\sigma$ phase 
existed in alloys with higher $\mathrm{Cr} / \mathrm{Mo}$ ratio in comparison with the formation of $\mathrm{P}$ phase.

\section{Conclusions}

Microstructural instability involving the formation of TCP phases was investigated in a series of single crystal superalloys containing different levels of $\mathrm{Co}, \mathrm{Cr}$, Mo and $\mathrm{Ru}$ additions in this study. The following conclusions can be drawn:

(1) TCP phases existed with various morphologies and compositions in different experimental alloys during the thermal exposure at $1100^{\circ} \mathrm{C}$. More additions of $\mathrm{Cr}$ and Mo promoted the TCP phase formation, while $\mathrm{Co}$ and $\mathrm{Ru}$ had a positive effect on microstructural stability.

(2) Co and $\mathrm{Ru}$ additions decreased the partitioning ratios of $\mathrm{Re}, \mathrm{Cr}$, Mo and $\mathrm{W}$ to different degrees, while increasing $\mathrm{Cr}$ and Mo contents induced the opposite effect. Effects of these four alloying additions on the elemental partitioning behavior between $\gamma$ and $\gamma^{\prime}$ phases contributed to their corresponding influence on TCP phase formation.

(3) The contents of $\mathrm{Co}, \mathrm{Cr}$ and Mo in these alloys affected the types of TCP phases significantly, while $\mathrm{Ru}$ additions showed a negligible effect. Alloys containing high level of Co addition had a tendency to $\mathrm{R}$ phase formation after thermal exposure at $1100^{\circ} \mathrm{C}$. Meanwhile, the formation of $\sigma$ and $\mathrm{P}$ phases were prone to form in alloys containing low level of Co addition. $\sigma$ phase existed in alloys with higher $\mathrm{Cr} / \mathrm{Mo}$ ratio in comparison with the formation of $\mathrm{P}$ phase.

The financial supports provided by National Natural Science Foundation of China (Grant No. 51271015), National Basic Research Program of China (Grant No. 2010CB631201) and National High Technology Research and Development Program of China (Grant No. 2012AA03A513 and 2012AA03A511) are gratefully acknowledged.

\section{References}

[1] R.C. Reed, The superalloys: Fundamentals and applications, (Cambridge University Press, Cambridge, 2006)

[2] A.C. Yeh, A. Sato, T. Kobayashi, H. Harada, Mater. Sci. Eng. A, 490, 445 (2008)
[3] M. Pessah, P. Caron, T. Khan, Superalloys 1992, TMS, 567 (1992)

[4] T.M. Pollock, S. Tin, Journal of Propulsion and Power, 22, 361 (2006)

[5] J.Y. Chen, Q. Feng, L.M. Cao, Z.Q. Sun, Mater. Sci. Eng. A, 528, 3791 (2011)

[6] C.M.F. Rae, R.C. Reed, Acta Mater., 49, 4113 (2001)

[7] K.S. O'Hara, W.S. Walston, E.W. Ross, R. Darolia, US Patent: 5482789 (1996)

[8] S. Walston, A. Cetel, R. MacKay, K. O’Hara, D. Duhl, R. Dreshfield, Superalloys 2004, TMS, 15 (2004)

[9] L.J. Carroll, Q. Feng, T.M. Pollock, Metall. Mater. Trans. A, 39, 1290 (2008)

[10] C.H. Lund, M.J. Woulds, J. Hockin, Superalloys 1968, TMS, 25 (1968)

[11] T.E. Strangman, G.S. Hoppin III, C.M. Phipps, K. Harris, R.E. Schwer, Superalloys 1980, TMS, 215 (1980)

[12] W.Z. Wang, T. Jin, J.L. Liu, X.F. Sun, H.R. Guan, Z.Q. Hu, Mater. Sci. Eng. A, 479, 148 (2008)

[13] R. Bürgel, J. Grossmann, O. Lusebrink, H. Mughrabi, F. Pyczak, R.F. Singer, A. Volek, Superalloys 2004, TMS, 25 (2004)

[14] G.L. Erickson, Superalloys 1996, TMS, 35 (1996)

[15] L.J. Carroll, Q. Feng, J.F. Mansfield, T.M. Pollock, Metall. Mater. Trans. A, 37, 2927 (2006)

[16] J. Zhang, T. Murakumo, Y. Koizumi, T. Kobayashi, H. Harada, Metall. Mater. Trans. A, 35, 1911 (2004)

[17] R.A. MacKay, T.P. Gabb, A. Garg, R.B. Rogers, M.V. Nathal, NASA Report: 20120017919 (2012)

[18] Q. Shi, X. Ding, M. Wang, Y. Zheng, J. He, S. Tin, Q. Feng, Metall. Mater. Trans. A, 45, 1833 (2014)

[19] N. Yukawa, H. Adachi, Superalloys 1984, TMS, 523 (1984)

[20] J. Zhang, Z. Hu, Y. Ata, M. Morinaga, N. Yukawa, Metall. Mater. Trans. A, 24, 2443 (1993)

[21] SAE International Standard, AS5491C: Calculation of Electron Vacancy Number in Superalloys (2007)

[22] R.C. Reed, A.C. Yeh, S. Tin, S.S. Babu, M.K. Miller, Scripta Mater., 51, 327 (2004)

[23] T. Yokokawa, M. Osawa, K. Nishida, T. Kobayashi, Y. Koizumi, H. Harada, Scripta Mater., 49, 1041 (2003)

[24] R.A. Hobbs, L. Zhang, C.M.F. Rae, S. Tin, Metall. Mater. Trans. A, 39, 1014 (2008)

[25] M. Karunaratne, C. Rae, R. Reed, Metall. Mater. Trans. A, 32, 2409 (2001) 